Jurnal Bidan Cerdas
e-ISSN: 2654-9352 dan p-ISSN: 2715-9965
Volume 3 Nomor 2, 2021
DOI: 10.33860/jbc.v3i2.420
Website: http://jurnal.poltekkespalu.ac.id/JBC
Penerbit: Poltekkes Kemenkes Palu

\title{
Kombinasi Swedish Massage dan Aromaterapi Lemon untuk Menurunkan Nyeri Post Sectio Caesarea
}

\author{
Dafrosia Darmi Manggasa $\triangle 1 D$ \\ Poltekkes Kemenkes Palu \\ 区Email korespondensi: dafrosiamanggasa@yahoo.com
}

Qopen
ARTICLE INFO
Article History:
Received: 2021-03-04
Accepted: 2021-04-25
Published: 2021-06-13

Kata Kunci:

Swedish massage;

Aromaterapi lemon;

Nyeri;

Sectio Caesarea.

\section{Keywords:}

Swedish massage; Lemon aromatherapy; Pain;

Sectio Caesarea;

\begin{abstract}
ABSTRAK
Pendahuluan: Persalinan buatan dengan prosedur Sectio Caesarea (SC) dapat mengakibatkan rasa nyeri pada pasien. Nyeri yang tidak tertangani dapat berdampak negatif pada ibu maupun bayi. Penanganan nyeri dapat menggunakan intervensi massage maupun aromaterapi yang memberi efek relaksasi. Penelitian ini bertujuan untuk menilai efektifitas dari kombinasi Swedish massage dengan aromaterapi lemon dalam menurunkan nyeri post SC. Metode: Quasi eksperimen dengan desain two group pre-post test. Penelitian dilaksanakan di RSUD Poso pada Bulan Oktober sampai Desember 2019. Sampel yaitu pasien post SC yang mengalami nyeri sebanyak 32 orang yang diambil dengan teknik purposive sampling. Intervensi Swedish massage dilakukan sebanyak 4 kali. Nyeri diukur sebelum intervensi dan setelah intervensi menggunakan Numeric Rating Scale. Analisis data menggunakan uji Wilcoxon dan Mann Whitney. Hasil: Penelitian ini menunjukkan pada kelompok intervensi kombinasi Swedish massage dengan aromaterapi lemon menunjukkan penurunan skor nyeri yang signifikan dengan nilai mean setelah intervensi 3,19 dan pada kelompok kontrol dengan intervensi Swedish massage saja nilai mean sebesar 3,88 , analisis statistik diperoleh nilai $\mathrm{p}=0,031$. Kesimpulan: Kombinasi Swedish massage dengan aromaterapi lemon efektif menurunkan skor nyeri pasien post SC, sehingga disarankan untuk menjadi salah satu intervensi keperawatan untuk menurunkan nyeri post SC.
\end{abstract}

ABSTRACT
Introduction: Artificial delivery with the Sectio Caesarea (SC) procedure can
cause pain in the patient. Pain that is left untreated can have a negative impact
on both the mother and the baby. Pain management can also use massage or
aromatherapy interventions that provide a relaxing effect. This study aims to
assess the effectiveness of combined therapy Swedish massage and lemon
aromatherapy in reducing post-SC pain. Methods: Quasi-experimental design
with two groups pre-post test. This study was conducted at Poso Regional
Hospital from October to December 2019 . The sample was 32 post-SC patients
who experienced pain who were taken using the purposive sampling technique.
Swedish massage intervention was carried out 4 times. The pain was measured
before intervention and after intervention using the Numeric Rating Scale. Data
analysis used the Wilcoxon and Mann-Whitney tests. Results: This study
showed that the intervention group with combined therapy Swedish massage and
lemon aromatherapy showed a significant reduction in pain scores with a mean
after the intervention of 3.19 and in the control group with Swedish massage only
the mean value was 3.88, statistical analysis obtained p-value 0.031.
Conclusion: The combined therapy Swedish massage and lemon aromatherapy
is effective in reducing the pain score of post-SC patients, so it is suggested to be
one of the nursing interventions to reduce post-SC pain.

Introduction: Artificial delivery with the Sectio Caesarea (SC) procedure can cause pain in the patient. Pain that is left untreated can have a negative impact on both the mother and the baby. Pain management can also use massage or aromatherapy interventions that provide a relaxing effect. This study aims to assess the effectiveness of combined therapy Swedish massage and lemon aromatherapy in reducing post-SC pain. Methods: Quasi-experimental design who experienced pain who were taken using the purposive sampling technique. Swedish massage intervention was carried out 4 times. The pain was measured before intervention and after intervention using the Numeric Rating Scale. Data analysis used the Wilcoxon and Mann-Whitney tests. Results: This study showed that the intervention group with combined therapy Swedish massage and emon aromatherapy showed a significant reduction in pain scores with a mean Conclusion: The combined therapy Swedish massage and lemon aromatherapy is effective in reducing the pain score of post-SC patients, so it is suggested to be

(C) 2021 by the authors. Submitted for possible open access publication under the terms and conditions of the Creative Commons Attribution (CC BY SA) license (https://creativecommons.org/licenses/by-sa/4.0/). 


\section{PENDAHULUAN}

Tindakan Sectio Caesarea (SC) kini semakin banyak dilakukan sebagai prosedur untuk menjaga keselamatan ibu dan bayi serta mengatasi penyulit pada saat persalinan normal. Peningkatan persalinan SC disebabkan antara lain karena disproporsi cephalo pelvic, kondisi preeklampsia atau eklamsia, kelainan letak bayi, placenta previa totalis, bayi kembar, kehamilan pada ibu usia dini atau usia lanjut, infeksi jalan lahir dan sebagainya. Persalinan SC merupakan persalinan buatan, dimana janin dilahirkan melalui insisi pada dinding perut dan dinding rahim dengan syarat rahim dalam keadaan utuh dan berat janin diatas 1000 gram atau umur kehamilan >28 minggu (Cunningham, 2012).

Angka persalinan dengan SC di berbagai negara mengalami peningkatan sejak tahun 2000 hingga 2015 sebesar $9 \%$. Tercatat penggunaan metode SC pada tahun 2000 sebanyak $12 \%$ dari total kelahiran, menjadi $21 \%$ pada 2015. (The Lancet, 2018). Menurut World Health Organization (WHO), Amerika latin dan wilayah karibia menjadi penyumbang angka metode sesar tertinggi yaitu 40,5\%, diikuti oleh Eropa 25\%, dan Afrika 7,3\% (World Health Organization (WHO), 2015). Berdasarkan hasil Riset Kesehatan Dasar (Riskesdas) di Indonesia tahun 2018 menunjukan pravelensi persalinan dengan SC adalah $17,6 \%$, tertinggi diwilayah DKI Jakarta $(31,3 \%)$ dan terendah di papua $(6,7 \%)$, dan untuk di Sulawesi Tengah tindakan SC sebanyak 15,3\% (Riskesdas, 2018).

Tindakan SC mengakibatkan robeknya jaringan dinding perut dan dinding uterus yang menyebabkan terjadinya gangguan kontinuitas jaringan sehingga ibu merasakan nyeri. Nyeri merupakan kondisi berupa perasaan tidak menyenangkan bersifat sangat subjektif karena perasaan nyeri berbeda pada setiap individu dalam hal skala atau tingkatannya, dan hanya individu tersebutlah yang dapat menjelaskan atau mengevaluasi rasa nyeri yang dialaminya (Hidayat, 2015)

Dampak yang ditimbulkan jika nyeri tidak ditangani yaitu tgerganggunya mobilisasi fisik, terhambatnya bounding attachment, activity daily living (ADL) terbatas, Inisiasi Menyusui Dini (IMD) tertunda atau tidak terpenuhi dengan baik, berkurangnya nutrisi bayi karena ibu masih nyeri akibat SC, menurunnya kualitas tidur, menjadi stres dan cemas, dan takut apabila dilakukan pembedahan kembali (Utami Sri, 2014). Nyeri pada pasien post SC perlu mendapatkan penanganan agar tidak berdampak negatif bagi ibu maupun bayi yang dilahirkan. Selama ini pananganan nyeri melalui penggunaan obat analgesik, namun terdapat intervensi secara non farmakologis yang sering diterapkan untuk menangani nyeri yang tidak menimbulkan efek samping maupun ketergantungan antara lain pemberian aromaterapi, tindakan massage, teknik pernafasan, akupuntur, trancutaneus electric nerve stimulations (TENS), kompres dan audionalgesia (Gondo, 2011)

Penelitian membuktikan intervensi yang dapat diberikan untuk menurunkan tingkatan nyeri tanpa memberikan efek samping dan ketergantungan pada pasien dengan nyeri antara lain pemberian aromaterapi massage (Abbasi, 2015). Intervensi massage untuk menurunkan tingkat nyeri post section caesarea yaitu Swedish massage yang terdiri dari 5 gerakan yaitu efflurage (mengusap), petrissage (memijat), friction (menggosok), tapotement (memukul) dan vibration (menggerus). Stimulasi kulit dengan cara Swedish massage pada jaringan otot dapat mengurangi tingkat nyeri dimana pijatan dapat menghasilkan impuls yang dikirim melalui serabut saraf besar yang berada dipermukaan kulit, serabut saraf ini akan tertekan, impuls nyeri dihambat sehingga otak tidak mempersepsikan nyeri (Solehati et al., 2018)

Selain massage, aromaterapi juga terbukti efektif menurunkan nyeri. Berdasarkan hasil penelitian sebelumnya membuktikan bahwa aromaterapi lemon 
efektif dalam menurunkan nyeri post section caesarea (Manurung R, 2018; Namazi et al., 2014; Sri et al., 2018). Penelitian berikutnya dilakukan oleh Cahyati, (2018) dan Youssef \& Hassan, (2017) bahwa Swedish massage efektif untuk menurunkan nyeri pada pasien post operasi. Aromaterapi merupakan terapi atau pengobatan dengan menggunakan bau-bauan yang berasal dari tumbuh-tumbuhan, bunga, pohon yang berbau harum dan enak. Minyak esensial lemon mengandung aroma terapi yang dapat berfungsi menurunkan nyeri. Minyak esensial lemon memiliki kandungan limeone 66-80, geranil asetat, netrol, terpine 6-14\%, a pinene 1-4\% dan mrcyne (Suwanti et al., 2018). Limeone dapat menghambat sistem kerja prostaglandin karena sifat antioksidan yang dimiliki senyawa kimia jeruk ini saat terjadinya kerusakan sel, senyawa ini akan mengikat enzim endoperoksida. Enzim endoperoksida adalah salah satu enzim yang bertanggung jawab terhadap pembentukan prostaglandin, saat enzim ini telah terikat pembentukan mediatormediator nyeri akan terhambat sehingga dapat mengurangi rasa nyeri (Namazi et al., 2014). Penelitian ini bertujuan untuk menilai efektifitas dari intervensi kombinasi Swedish massage dengan aromaterapi lemon dalam menurunkan nyeri post SC.

\section{METODE PENELITIAN}

Penelitian ini merupakan penelitian quasi eksperimen dengan desain two group pre-post test design. Penelitian terdiri atas 2 kelompok yaitu kelompok kontrol yang mendapatkan intervensi Swedish massage dan kelompok perlakuan yang mendapatkan intervensi kombinasi Swedish massage dengan aromaterapi lemon. Penelitian di laksanakan di Rumah Sakit Umum Daerah Poso pada bulan Agustus sampai Desember 2019. Populasi penelitian adalah seluruh ibu post SC di RSUD Poso dan sampel yaitu ibu post SC yang mengalami nyeri di RSUD Poso yang berjumlah 32 orang yang dibagi dalam 2 kelompok dengan cara simple random sampling. Pengambilan sampel dengan cara purposive sampling. Kriteria inklusi yaitu (1) anastesi spinal, (2) kesadaran compos mentis (3) skala nyeri $>3$ ). Kriteria ekslusi yaitu (1) ibu dengan penyakit penyerta (luka lain selain luka SC, gangguan respirasi, gangguan kardiovaskuler), (2) masalah psikologis seperti depresi, atau kecemasan. Intervensi Swedish massage dilakukan sebanyak 4 kali masing-masing selama 15 menit. Intervensi pertama dilakukan 6 jam pasca SC dan intervensi selanjutnya setiap rentang 6 jam. Massage dilakukan pada area otot trapezius kiri dan kanan, otot deltoid dan bisep kiri dan kanan, kepala, dahi, kedua kaki. Instrumen penelitian adalah kuesioner yang berisi data karakteristik reponden yang memuat umur, pendidikan, pekerjaan, paritas dan indikasi SC. Skor nyeri diukur menggunakan skala Numeric Rating Scale dengan rentang nyeri 0-10. Skor nyeri dinilai sebelum intervensi dan setelah intervensi ke 4 yaitu pada hari kedua. Analisa data menggunakan uji Wilcoxon dan Mann Whitney.

\section{HASIL PENELITIAN}

Berdasarkan hasil pengolahan data dan analisis data, maka disajikan hasil penelitian berupa gambaran karakteristik responden berdasarkan umur, pendidikan, pekerjaan, paritas dan indikasi SC, perbedaan rerata skor nyeri sebelum dan setelah intervensi dan perbandingan skor nyeri setelah intervensi Swedish massage dan kombinasi Swedish massage dengan aromaterapi lemon. 
Tabel 1. Karakteristik Responden Berdasarkan Umur, Pendidikan, Pekerjaan, Paritas dan Indikasi SC di RSUD Poso

\begin{tabular}{|c|c|c|}
\hline Karakteristik & Frekuensi & Persentase (\%) \\
\hline \multicolumn{3}{|l|}{ Umur } \\
\hline$<20$ Tahun & 3 & 9,4 \\
\hline 20-35 Tahun & 21 & 65,6 \\
\hline$>35$ Tahun & 8 & 25 \\
\hline \multicolumn{3}{|l|}{ Pendidikan } \\
\hline SD & 2 & 6,3 \\
\hline SMP & 5 & 15,6 \\
\hline SMA & 14 & 43,8 \\
\hline PT & 11 & 34,4 \\
\hline \multicolumn{3}{|l|}{ Pekerjaan } \\
\hline Bekerja & 21 & 65,6 \\
\hline Tidak Bekerja & 11 & 34,4 \\
\hline \multicolumn{3}{|l|}{ Paritas } \\
\hline Primipara & 7 & 21,9 \\
\hline Multipara & 19 & 59,4 \\
\hline Grande Multipara & 6 & 18,8 \\
\hline \multicolumn{3}{|l|}{ Indikasi SC } \\
\hline Bekas SC Sebelumnya & 18 & 56,3 \\
\hline Letak Lintang & 6 & 18,8 \\
\hline Oligohidramnion & 3 & 9,4 \\
\hline Cefal Pelvic Disproporsi & 1 & 3,1 \\
\hline Plasenta Previa Marginalis & 1 & 3,1 \\
\hline Anak Dibawah Umur & 1 & 3,1 \\
\hline Kala 1 lama + Gawat Janin & 1 & 3,1 \\
\hline Bayi Besar & 1 & 3,1 \\
\hline
\end{tabular}

Sumber: data primer, 2019

Tabel 1 menunjukkan bahwa mayoritas responden berada pada rentang usia 2035 tahun $(65,6 \%)$, pendidikan SMA (43,8\%), mayoritas bekerja $(65,6 \%)$, multipara $(59,4 \%)$, dan berdasarkan indikasi SC yaitu mayoritas atas indikasi bekas SC sebelumnya (56,3\%), di ikuti indikasi letak lintang (18,8\%).

Tabel 2. Perbedaan Rerata Skor Nyeri Post SC Sebelum dan Setelah Intervensi di RSUD Poso

\begin{tabular}{lccc}
\hline \multicolumn{1}{c}{ Kelompok } & N & Mean & Nilai $\boldsymbol{p}$ \\
\hline Swedish massage & & & \\
$\quad$ Sebelum Intervensi & 16 & 6,63 & $<0,001$ \\
$\quad$ Setelah Intervensi & 16 & 3,88 & \\
Kombinasi Swedish massage + & & & \\
Aromaterapi Lemon & & & \\
$\quad$ Sebelum Intervensi & 16 & 6,75 & $<0,001$ \\
$\quad$ Setelah Intervensi & 16 & 3,19 & \\
\hline Sumber: data prmer, 2019 & & &
\end{tabular}

Tabel 2 menunjukkan bahwa rerata skor nyeri post SC pada kelompok Swedish massage sebelum intervensi yaitu 6,63 dan setelah intervensi yaitu 3,88. Hasil 
analisis statistik menggunakan uji wilcoxon diperoleh nilai $\mathrm{p}<0,001$, sehingga disimpulkan bahwa ada penurunan yang signifikan rerata skor nyeri sebelum dan setelah pemberian intervensi Swedish massage. Pada kelompok kombinasi Swedish massage dengan aromaterapi lemon rerata skor nyeri sebelum intervensi yaitu 6,75 dan setelah intervensi yaitu 3,19 . Hasil analisis statistik menggunakan uji wilcoxon diperoleh nilai $p=0,000<\alpha(0,05)$, sehingga di simpulkan bahwa ada penurunan yang signifikan rerata skor nyeri sebelum dan setelah pemberian intervensi kombinasi Swedish massage dengan aromaterapi lemon.

Tabel 3. Perbandingan Skor Nyeri Post SC Setelah Pemberian Intervensi Swedish massage dan Kombinasi Swedish massage + Aromaterapi Lemon di RSUD Poso

\begin{tabular}{lccr}
\hline \multicolumn{1}{c}{ Kelompok } & N & Mean & Nilai $\boldsymbol{p}$ \\
\hline $\begin{array}{l}\text { Swedish massage } \\
\text { Kombinasi Swedish massage + } \\
\text { Aromaterapi lemon }\end{array}$ & 16 & 3,88 & 0,031 \\
\hline
\end{tabular}

Tabel 3 menunjukkan bahwa rerata skor nyeri post SC setelah pemberian intervensi Swedish massage yaitu 3,88 dan rerata skor nyeri post SC setelah pemberian intervensi kombinasi Swedish massage + aromaterapi lemon yaitu 3,19. Hasil analisis statistik menggunakan uji Mann Whitney di peroleh nilai $p=0,031$, maka di simpulkan bahwa terdapat perbedaan yang signifikan skor nyeri post SC setelah intervensi antara kelompok Swedish massage dengan kelompok kombinasi Swedish massage + aromaterapi lemon.

\section{PEMBAHASAN}

Persalinan dengan tindakan sectio caesarea merupakan pembedahan pada perut dengan melakukan irisan dinding perut dan rahim untuk mengeluarkan bayi. Tindakan tersebut menyebabkan robeknya jaringan dinding perut dan uterus sehingga setelah tindakan bu merasakan nyeri (Abbasi, 2015). Nyeri merupakan perasaan yang tidak menyenangkan dan pada masing-masing individu perasaan nyeri dapat dipersepsikan berbeda-beda karena bersifat sangat subjektif termasuk dalam hal skala atau tingkatannya, dan hanya orang tersebutlah yang dapat melaporkan atau mengevaluasi rasa nyeri yang dialaminya (Hidayat, 2015). Nyeri dapat diatasi dengan menggunakan obat-obatan analgetik misalnya morphine sublimaze, stadol, demersol dan lain-lain namun tindakan komplementer merupakan salah satu alternatif penatalaksanan nyeri yang tidak memiliki efek samping dan ketergantungan antara lain pemberian aromaterapi, tindakan massage, teknik pernafasan, akupuntur, trancutaneus electric nerve stimulations (TENS), kompres dan audionalgesia (Gondo, 2011)

Hasil penelitian ini menunjukkan bahwa terdapat penurunan rerata skor nyeri sebelum dan setelah pemberian intervensi Swedish massage, dan hasil uji statistik menunjukkan terdapat perbedaan yang signifikan skor nyeri sebelum dan setelah pemberian intervensi Swedish massage sehingga disimpulkan bahwa Swedish massage efektif menurunkan nyeri post SC. Penurunan skor nyeri post SC terjadi karena adanya stimulus berupa pijatan pada tubuh yang meninmbulkan efek relaksasi. Swedish massage adalah jenis terapi yang paling umum digunakan yang sering dikenal sebagai pijat ringan atau relaksasi. Terapi Swedish massage dapat meningkatkan sirkulasi, yang membantu tubuh menjadi rileks dan berenergi dengan 
menghilangkan ketegangan otot dan rasa sakit sehingga meningkatkan kesehatan dan kesejahteraan secara keseluruhan (Youssef \& Hassan, 2017).

Penelitian pada pasien post operasi didapatkan hasil penurunan skala nyeri yang signifikan pada kelompok perlakuan yang menerima pijatan dibandingkan dengan kelompok kontrol yang hanya menerima perawatan biasa. Hal ini menujukkan bahwa adanya pengaruh Swedish massage dalam menurunkan nyeri pasien post operasi. (Youssef \& Hassan, 2017). Berdasarkan teori gate control oleh Melzack dan Wall bahwa sebuah mekanisme di otak berbuat seperti sebuah gerbang yang terbuka dan tertutup untuk meningkatkan atau mengurangi aliran impuls saraf ke sistem saraf pusat. Gerbang yang terbuka memungkinkan terjadinya aliran impuls saraf sehingga otak menerima pesan nyeri sehingga nyueri dipersepsikan. Gerbang yang tertutup tidak memungkinkan saraf mengalirkan pesan nyeri ke otak sehingga nyeri tidak dipersepsikan. Mekanisme menutup gerbang untuk menghambat impuls nyeri yang akan disampaikan ke otak salah satunya dengan stimulasi kutaneus yaitu dalam bentuk Swedish massage yang dapat membantu serabut saraf beta-A untuk melepaskan neurotransmiter penghambat (neuromodulator), salah satunya yaitu opiat endogen seperti endorfin. Neuromodulator ini akan menutup mekanisme pertahanan dengan menghambat pelepasan substansi-P dan memblok transmisi nyeri. Penelitian lainnya dilakukan oleh Cahyati, (2018) Swedish massage terbukti efektif secara signifikan dalam menurunkan tingkat nyeri pasien post CABG. Swedish massage juga terbukti efektif untuk berbagai kondisi nyeri muskuloskeletal. Massage dapat menurunkan ketegangan otot, meningkatkan sirkulasi sehingga meningkatkan relaksasi dan menurunkan kecemasan. Efek dari relaksasi dapat meningkatkan suasana hati.

Pada kelompok yang diberi intervensi kombinasi Swedish massage dengan aromaterapi lemon juga menunjukkan penurunan skor nyeri post SC sebelum dan setelah intervensi. Hasil analisis statistik menunjukkan terdapat perbedaan yang signifikan skor nyeri sebelum dan setelah intervensi sehingga disimpulkan bahwa intervensi kombinasi Swedish massage dengan aromaterapi lemon efektif menurunkan nyeri post SC. Berdasarkan hasil penelitian di peroleh rerata skor nyeri post SC setelah intervensi kombinasi Swedish massage dengan aromaterapi lemon lebih rendah $(3,19)$ dari rerata skor nyeri setelah intervensi Swedish massage saja $(3,88)$. Hasil analisis statistik menggunakan uji Mann Whitney terdapat perbedaan yang signifikan skor nyeri post SC setelah intervensi antara kelompok Swedish massage dengan kelompok kombinasi Swedish massage + aromaterapi lemon sehingga di simpulkan bahwa kombinasi Swedish massage dengan aromaterapi lemon efektif dalam menurunkan nyeri post SC dibandingkan dengan Swedish massage saja. Aromaterapi merupakan metode dengan menggunakan esential oil untuk meningkatkan kesehatan fisik, psikis, spirit dan menurunkan nyeri (Koesmardiyah, 2009). Aromaterapi lemon memiliki komponen seperti linalool, limonene bergamot, farnesol, geranial dan beberapa komponen lainnya. Penggunaan aromaterapi dilakukan secara inhalasi atau penggunaan topikal setelah di encerkan dalam carrier oil.

Menurut penelitian Manurung (2018) membuktikan bahwa aromaterapi lemon mempunyai efek yang signifikan terhadap penurunan nyeri post sectio caesraea, yang disebabkan salah satu komponen yang terkandung dalam lemon yaitu linalool berfungsi untuk menstabilkan sistem saraf sehingga dapat menimbulkan efek tenang dan efek analgesic. Aromaterapi yang dihirup akan ditransferkan ke pusat penciuman yang berada dipangkal otak. Pada tempat ini sel neuron akan menafsirkan bau tersebut dan akan mengantarkan ke sistem limbik, dari sistem 
limbik pesan tersebut akan dihantarkan ke hipotalamus, selanjutnya diantar oleh sistem sirkulasi dan agen kimia kepada tubuh yang membutuhkan (Setyoadi, 2011)

Pemberian aromaterapi lemon atau jeruk masam pada ibu post section caesarea menunjukan adanya penurunan nyeri yang disebabkan oleh komponen linalool dan limonene yang memiliki efek analgetik dan penenang. Limonene merupakan senyawa utama yang bertugas menghambat kerja prostaglandin karena sifat antioksidan yang dimilikinya. Saat terjadi kerusakan sel senyawa ini akan mengikat enzim endoperoksida yang bertanggung jawab dalam pembentukan prostaglandin, sehingga saat enzim ini berhasil diikat pembentukan mediator-mediator nyeri akan terhambat sehingga nyeri dapat berkurang (Namazi et al., 2014). Selain itu senyawa yang terkandung dalam lemon ini juga efektif untuk menurunkan tingkat nyeri menstruasi (Suwanti et al., 2018).

Penelitian ini juga sejalan dengan penelitian Astuti, 2015 menunjukkan adanya penurunan nyeri dan kecemasan setelah diberikan aromaterapi lemon pada ibu melahirkan kala 1 (Astuti, 2015). Aromaterapi menghasilkan hormon endorphin yang berfungsi untuk menghilangkan rasa sakit dan serotonin yang memberikan efek senang sehingga kecemasan dapat menurun. Pada penelitian ini terbukti kombinasi Swedish massage dengan aromaterapi lemon efektif menurunkan nyeri post SC. Aromaterapi lemon yang diberikan secara inhalasi menggunakan difuser sambil melakukan Swedish massage pada pasien nyeri post SC akan memaksimalkan efek relaksasi dari massage dan aromaterapi lemon tersebut. Pasien merasa lebih relaks, suasana hati tenang sehingga rasa nyeri akan terdistraksi. Penatalaksanaan nyeri post SC secara non farmakologis melalui intervensi kombinasi Swedish massage dan aromaterapi lemon secara signifikan efektif dalam menurunkan intensitas nyeri.

\section{SIMPULAN DAN SARAN}

Kesimpulan bahwa kombinasi Swedish massage dengan aromaterapi lemon efektif menurunkan skor nyeri post-SC. Saran bagi perawat dan bidan di ruangan perawatan nifas diharapkan dapat menerapkan intervensi kombinasi Swedish massage dengan aromaterapi lemon untuk menurunkan nyeri post SC dan meningkatkan kenyaman pasien. Peneliti selanjutnya dapat mengembangkan penelitian ini dengan melakukan pengukuran skor nyeri secara berkala dan membandingkan dengan intervensi lain untuk menurunkan nyeri.

\section{DAFTAR PUSTAKA}

Abbasi, M. (2015). A comparative study on the concept of convulsion in traditional Iranian medicine and classic medicine. Avicenna Journal of Phytomedicine, 5(Suppl. 1), 1. https://ajp.mums.ac.ir/article_5454_8900156ff21a8bf04ed2e00ce4c58eed.pdf

Astuti, W. (2015). Pengaruh Aromaterapi Bitter Orange Terhadap Nyeri Dan Kecemasan Fase Aktif Kala 1. The 2nd University Research Coloqium, 371-382. https://jurnal.unimus.ac.id/index.php/psn12012010/article/view/1613

Cahyati, A. (2018). Efektifitas Swedish Massage terhadap Tingkat Nyeri dan Tekanan Darah Pasien Pasca Bedah Jantung. Jurnal Buletin Media Informasi Kesehatan, 14(2), 85-94. http://ejurnal.poltekkestasikmalaya.ac.id/index.php/BMl/article/view/210

Cunningham, F. G. et all. (2012). Obstetri Wiliams (23rd ed). Penerbit Buku Kedokteran EGC.

Gondo, H. . (2011). Pendekatan NonFarmakologis untuk Mengurangi Nyeri Saat Persalinan. $\begin{array}{llll}\text { Jurnal Cermin } & 158 .\end{array}$ https://nanopdf.com/download/pendekatan-non-farmakologis-untuk-menguranginyeri_pdf

Hidayat, A. A. (2015). Pengantar Kebutuhan Dasar Manusia (2 Buku 2). Salemba Medika. 
Koesmardiyah. (2009). A-Z Aromaterapi Untuk Kesehatan, Kebugaran, dan Kecantikan. Lily Publisher.

Manurung R, N. E. (2018). Pengaruh Aroma Terapi Lemon Terhadap Penurunan Di Rumah Sakit Umum Imelda Pekerja Indonesia Medan Tahun 2018. Jurnal IImiah Keperawatan Imelda, 5(1), 5-11. https://doi.org/10.2411/jikeperawatan.v5i1.301

Namazi, M., Ali Akbari, S. A., Mojab, F., Talebi, A., Majd, H. A., \& Jannesari, S. (2014). Effects of citrus Aurantium (bitter orange) on the severity of first-stage labor pain. Iranian Journal of Pharmaceutical Research, 13(3), 1011-1018. https://doi.org/10.22037/ijpr.2014.1553

Riskesdas. (2018). Laporan Nasional Riset Kesehatan Dasar. Report of Indonesia Basic Health Survey 2018.

Setyoadi. (2011). Terapi Modalitas Keperawatan Pada Klien Psikogeratik. Salemba Medika.

Solehati, T., Kosasih, C. E., Jayanti, T. N., Ardiyanti, A., Sari, R. I., Siska, G. A., \& Utari, A. D. (2018). Terapi nonfarmakologi nyeri padapersalinan: Jurnal Keperawatan Muhammadiyah, 3(1), 50-73. $\quad$ http://journal.umsurabaya.ac.id/index.php/JKM/article/view/1568

Sri, M., Wahyuningsih, H., \& Hapsari, E. D. (2018). Efek Pemberian Aromaterapi Jeruk Masam Terhadap Intensitas Nyeri Pasca Bedah Sesar. The 7th University Research Colloqium 2018,

227-235. http://repository.urecol.org/index.php/proceeding/article/view/128

Suwanti, S., Wahyuningsih, M., \& Liliana, A. (2018). Pengaruh Aromaterapi Lemon (Cytrus) terhadap Penurunan Nyeri Menstruasi pada Mahasiswi di Universitas Respati Yogyakarta. Jurnal Keperawatan Respati, 5(1), 345-349. http://nursingjurnal.respati.ac.id/index.php/JKRY/article/view/131

Utami Sri. (2014). Efektivitas Aromaterapi Bitter Orange Terhadap Penurunan Nyeri Post Partum Setio Caesarea. Unnes Journal Of Public Health, 3(1), 1-10. https://journal.unnes.ac.id/sju/index.php/ujph/article/view/12422

World Health Organization (WHO). (2015). Caesarean Section should only be performed when medically necessary. https://www.who.int/reproductivehealth/topics/maternal_perinatal/cs-statement/en/

Youssef, N. F. A., \& Hassan, A. D. A. (2017). The Effect of hand and foot massage on alleviating pain and anxiety of abdominal post-operative patients at a University Hospital: A randomized control trial. IOSR Journal of Nursing and Health Science, 06(03), 56-65. https://doi.org/10.9790/1959-0603035665 